\title{
DEKOLONISASI MULTIDRUG-RESISTANT ORGANISMS (MDRO's) DENGAN CUC TANGAN SEBAGAI UPAYA PENGENDALIAN RESISTENSI ANTIBIOTIK PADA KELOMPOK MASYARAKAT DI KABUPATEN BANYUMAS
}

\author{
Oleh: \\ Rani Afifah Nur Hestiyani, Nia Krisniawati, I Dewa Sang Ayu Putu Peramiarti, Tri Okmawati \\ Handini, Galuh Yulieta Nitihapsari, Anriani Puspita Karunia Ning Widi, Dwi Utami Anjarwati* \\ Fakultas Kedokteran, Universitas Jenderal Soedirman, Purwokerto \\ rani.hestiyanti@unsoed.ac.id
}

\begin{abstract}
Abstrak
Resistensi antibiotik menjadi permasalahan global karena dapat meningkatkan risiko penyebaran penyakit infeksi dan biaya pengobatan akibat munculnya Multidrug Resistant Organism (MDRO's) tidak hanya di Rumah Sakit tapi juga di masyarakat. Salah satu langkah upaya pengendaliannya, yaitu dekolonisasi MDRO's dengan cuci tangan metode WHO. Tujuan pengabdian masyarakat ini adalah untuk meningkatkan pengetahuan dan keterampilan masyarakat tentang dekolonisasi MDRO dengan metode cuci tangan. Metode yang digunakan, meliputi penyuluhan masalah resistensi antibiotik dan upaya pengendaliannya dan pelatihan mengenai metode cuci tangan menurut WHO sebagai salah satu langkah pengendalian resistensi antibiotik. Hasil pengabdian masyarakat ini adalah masyarakat mampu mempraktekan secara mandiri metode cuci tangan menurut WHO. Respon mitra terhadap pelatihan cukup tinggi dilihat dari antusiasme dan ketertarikan yang tinggi.
\end{abstract}

Kata Kunci : cuci tangan, dekolonisasi, Multidrug Resistant Organism (MDRO), resistensi antibiotik

\begin{abstract}
Antibiotic resistance is a global problem, because it can increase the risk of spreading infectious diseases and medical cost due to the emergence of Multidrug Resistant Organisms (MDRO's) not only in hospitals but also in the community. One of the step to control it namely the decolonization of MDRO's by washing the hands of the WHO method. The purpose of this community service was to improve the community's knowledge and skills regarding MDRO's decolonization by hand washing. The method use was counseling about antibiotic resistance and efforts to control and training on hand washing according to WHO as one of the measures to control antibiotic resistance. The results of this community services are that the community is able to practice independently the $\mathrm{WHO}$ hand washing method. The response of partners to the training the WHO hand washing method. The response of partners to the training was very good, seen from their enthusiasm and high interest.
\end{abstract}

Keywords: antibiotic resistance, decolonization, hand wash, Multidrug Resistant Organism (MDRO's)

\section{PENDAHULUAN}

Resistensi antibiotik merupakan permasalahan global yang harus dikendalikan karena dapat menurunkan efektivitas pengobatan penyakit infeksi, meningkatkan risiko penularan penyakit infeksi dan meningkatkan biaya kesehatan (Handayani et al., 2017). Antibiotik menjadi tidak efektif untuk mengobati penyakit infeksi karena munculnya strain bakteri yang resisten seperti Multidrug-resistant organisms (MDRO's). MDRO's yang berkembang karena penggunaan antibiotik tidak terkendali antara lain Methicilin resistant Staphylococcus aureus (MRSA), Vancomycin resistant
Staphylococcus aureus (VRSA), Extended spectrum betalactamase (ESBL), dan lain-lain (WHO, 2014).

Kejadian resistensi antibiotik tidak hanya ditemukan pada pasien yang dirawat di rumah sakit, tetapi ditemukan pula di masyarakat. Hal ini seperti yang dilaporkan oleh Santosaningsih et al. (2011) bahwa S. aureus pada komunitas masyarakat di Malang lebih resisten dibandingkan di rumah sakit. Penelitian resistensi antibiotik di daerah Banyumas memberikan informasi tentang karier MRSA pada petugas kesehatan di rumah sakit swasta sebanyak 14\%, sedangkan di rumah sakit pemerintah sebesar 25\% (Anjarwati et al., 2011). Pada awal 
tahun 2018, penelitian tim Fakultas Kedokteran Unsoed menemukan karier $E$. coli penghasil ESBL pada mahasiswa angkatan 2014 sebanyak 26,8\% dan berhubungan dengan penggunaan antibiotik yang tidak bijak (Ulla et al., 2018). Data ini menunjukkan bahwa MRSA ditemukan pula di masyarakat Kabupaten Banyumas dan sekitarnya.

Upaya pengendalian resistensi antibiotik di masyarakat dapat dilakukan dengan dua langkah, yaitu penggunaan antibiotik secara bijak dan mencegah penyebaran mikroba resisten. Menurut Kurniawati et al. (2015) dan Permenkes (2015), pencegahan penyebaran mikroba resisten dapat dilakukan dengan tindakan dekolonisasi bakteri dengan mencuci tangan.

Metode mencuci tangan yang standar adalah metode mencuci tangan menurut WHO. Metode cuci tangan menurut WHO sebenarnya merupakan langkah pencegahan penyebaran bakteri resisten di rumah sakit atau tempat pelayanan kesehatan yang lain (WHO, 2009). Namun, prosedur sederhana yang memungkinkan hal ini dapat diterapkan dalam kehidupan sehari-hari adalah melakukan dekolonisasi bakteri yang resisten pada karier di masyarakat.

Salah satu kelompok masyarakat di Kabupaten Banyumas yang berpotensi untuk melakukan penyuluhan dan pelatihan adalah kelompok pemberdayaan wanita Posdaya Rambutan yang beralamat di Jl. Kalijaga RW 2, Berkoh, Kabupaten Banyumas. Kelompok pemberdayaan tersebut memiliki kegiatan yang berjalan rutin, aktif dan bervariasi. Survey pendahuluan yang dilakukan oleh tim FK Unsoed pada tahun 2018 dalam memberikan informasi bahwa sosialisasi cara dekolonisasi bakteri resisten secara mandiri dengan metode cuci tangan menurut WHO belum pernah dilakukan pada kelompok pemberdayaan posyandu Rambutan, Berkoh. Keaktifan kelompok Posyandu Rambutan dan respon positif terhadap informasi yang bermanfaat, sangat berperan strategis sebagai agen atau kader masyarakat dalam upaya pengendalian resistensi antibiotik.

Pengendalian resistensi antibiotik memerlukan upaya komprehensif dari berbagai unsur baik Pemerintah sebagai regulator, tenaga kesehatan, farmasi, masyarakat, serta dunia pendidikan (Permenkes, 2015). Keterlibatan semua unsur tersebut dalam pengendalian resistensi antibiotik diharapkan dapat memutus rantai masalah resistensi antibiotik. Peran domestik anggota posyandu sebagai ibu yang mengatur logistik dalam rumah tangga sangat sesuai untuk mengemban tugas sebagai kader masyarakat. Hal ini bertujuan sebagai upaya meningkatan kebiasaan dekolonisasi bakteri secara mandiri dengan mencuci tangan untuk mencegah penularan bakteri resisten. Usaha tersebut dapat dimulai dari individu beserta keluarga sebagai unit masyarakat terkecil. Tugas berikutnya adalah bersama-sama anggota posyandu yang lain berkomitmen mencegah penyebaran bakteri resisten dalam komunitas di wilayahnya. Kegiatan serupa yang dijalankan secara konsisten dan kontinyu pada akhirnya dapat berperan dalam mengendalikan resistensi antibiotik pada wilayah yang lebih luas sampai ke tingkat nasional.

Kegiatan pengabdian masyarakat ini bertujuan untuk meningkatkan pengetahuan mengenai masalah resistensi antibiotik yang bisa terjadi di masyarakat dan upaya pengendaliannya. Selain itu meningkatkan keterampilan masyarakat dalam mempraktekan metode cuci tangan untuk mengatasi penyebaran MDRO's yang diharapkan dapat dipraktekkan dalam kehidupan sehari-hari.

\section{METODE}

Metode yang digunakan pada kegiatan pengabdian masyarakat ini adalah dengan sosialisasi dengan cara penyuluhan dan praktik metode mencuci tangan menurut WHO.

\section{Sasaran kegiatan}

Sasaran kegiatan adalah anggota kelompok pemberdayaan wanita Posdaya Rambutan, Berkoh, Kabupaten Banyumas.

\section{Tempat Kegiatan}

Tempat kegiatan di lokasi mitra di halaman Masjid Fastabiqul Khoirot yang beralamat di Jl. Kalijaga RW 2, Berkoh, Kabupaten Banyumas.

\section{Prosedur pelaksanaan}

a. Tim pelaksana pengabdian masyarakat memberikan penyuluhan mengenai masalah resistensi antibiotik yang terjadi di masyarakat beserta upaya pengendaliannya, salah satunya adalah dengan dekolonisasi bakteri resisten menggunakan metode mencuci tangan menurut $\mathrm{WHO}$ ).

b. Tim pelaksana pengabdian masyarakat mempraktikan langkah-langkah mencuci tangan menurut $\mathrm{WHO}$. 
c. Tim pelaksana pengabdian masyarakat melakukan pendampingan kepada masyarakat mengenai langkah-langkah mencuci tangan menurut WHO.

\section{HASIL DAN PEMBAHASAN}

Kegiatan pelaksanaan penyuluhan dan pendampingan diikuti praktik langkah-langkah mencuci tangan menurut WHO sebagai upaya dekolonisasi MDRO untuk mencegah penyebaran bakteri resisten dilaksanakan di tempat mitra, yaitu kelompok pemberdayaan wanita Posdaya Rambutan, Berkoh. Kegiatan penyuluhan diikuti oleh Ketua Posyada dan anggotanya, yang terdiri dari 75 peserta. Peserta terdiri dari 6 laki-laki dan 69 perempuan dengan rentang usia 18-80 tahun dan tingkat pendidikan terakhir dari tidak sekolah, SD, SLTP dan Strata 1. Jenis pekerjaan anggota terbanyak adalah ibu rumah tangga, sementara beberapa anggota yang lain merupakan karyawan swasta dan PNS.

Kegiatan pengabdian masyarakat diawali dengan penyuluhan mengenai informasi permasalahan resistensi antibiotik yang terjadi akibat bakteri yang telah resisten dengan berbagai macam antibiotik (MDRO's) dan upaya pengendaliannya. Salah satu metode yang dapat dilakukan sebagai upaya pengendalian bakteri MDRO's adalah dengan dekololonisasi bakteri dengan metode mencuci tangan menurut WHO. Metode ini sangat penting dilakukan sebelum melaksanakan aktivitas dan setelah melaksanakan aktivitas, dampak dan risiko apabila tidak mencuci tangan dan metode langkah-langkah mencuci tangan menurut WHO. Metode ini biasa digunakan lingkungan rumah sakit. Tetapi mengingat karier MDRO's di masyarakat sudah pada berpotensi sebagai agen penular, maka metode mencuci tangan menurut WHO dapat diterapkan dalam kehidupan sehari-hari.

Penyuluhan materi tersebut dilakukan dengan metode ceramah, untuk meningkatkan pemahaman, kemudian dilanjutkan dengan diskusi dan tanya jawab. Pada saat penyampaian materi oleh narasumber, peserta nampak antusias menyimak karena materi pentingnya mencuci tangan yang terlihat sederhana, namun ternyata penting untuk dilakukan dalam kehidupan sehari-hari.

Kegiatan selanjutnya, yaitu pendampingan praktik metode mencuci tangan menurut WHO. Langkah-langkah metode cuci tangan menurut WHO, yaitu : 1 . Ratakan sabun/handrub di kedua telapak tangan, 2. Gosok punggung dan sela-sela jari tangan kiri dengan tangan kanan dan sebaliknya, 3. Gosok dengan kedua telapak dan sela-sela jari, 4. Jari-jari dari kedua tangan saling mengunci, 5. Gosok ibu jari kiri berputar dalam genggaman tangan kanan dan lakukan sebaliknya, 6. Gosok dengan memutar ujung jari-jari tangan kanan di telapak tangan kiri dan sebaliknya.

Pada saat kegiatan praktik, tim pelaksana pengabdian menunjukkan praktik langkah-langkah mencuci tangan kemudian diikuti oleh para peserta pengabdian masyarakat. Masing-masing peserta penyuluhan juga diberikan sabun cuci tangan untuk memotivasi peserta agar melakukan praktik mencuci tangan menurut WHO dalam aktivitas sehari-hari di rumah.

Secara umum peserta antusias dalam mengikuti kegiatan penyuluhan dan praktik metode cuci tangan menurut WHO. Hal ini dibuktikan dengan banyaknya jumlah peserta yang melebihi target. Target awal peserta adalah 60 orang, namun yang hadir sejumlah 75 orang. Sebagian besar peserta antusias mengikuti kegiatan dari awal sampai akhir dan mampu mempraktekan metode cuci tangan menurut WHO (Tabel 1).

Tabel 1. Respon peserta

\begin{tabular}{|l|l|l|}
\hline No & Respon & $\%$ \\
\hline 1 & Baik & 97,3 \\
\hline 2 & Kurang & 2,6 \\
\hline
\end{tabular}

Pada akhirnya keterampilan mencuci tangan yang telah disosialisasikan akan dijadikan sebagai bahan untuk menyusun modul edukasi tentang pedoman dekolonisasi bakteri resisten dalam masyarakat pada tahun selanjutnya. Modul edukasi yang disusun bersama dengan kader posyandu Rambutan ini nantinya digunakan sebagai pedoman untuk diterapkan pada wilayah posyandu Rambutan dan didiseminasi pada kelompok masyarakat lain. Sehingga posyandu rambutan dapat menjadi kelompok masyarakat rujukan bagi kelompok lain dalam hal pengendalian resistensi antibiotik di Masyarakat. 


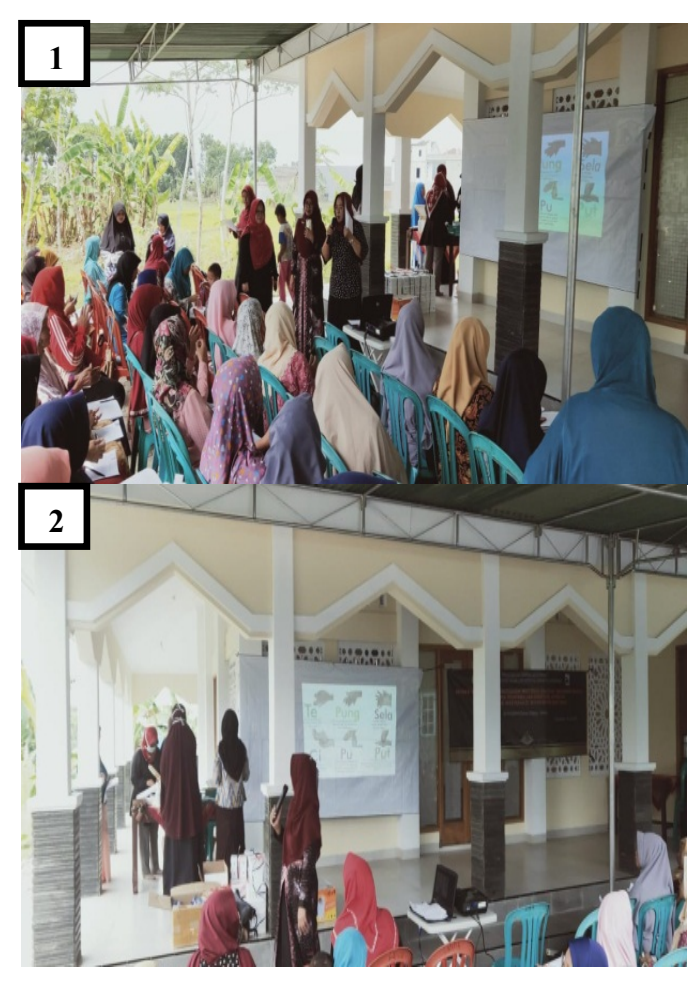

Gambar 1. Penyuluhan resistensi antibiotik Gambar 2. Penyuluhan tentang metode cuci tangan menurut WHO

Gambar 3. Tanya jawab materi penyuluhan Gambar 4. Pendampingan praktik cuci tangan metode $\mathrm{WHO}$

\section{SIMPULAN DAN SARAN}

Kegiatan pengabdian masyarakat ini berjalan lancar, tertib dan mencapai target mencapai 75 orang. Peserta juga antusias dalam mengikuti kegiatan, hal ini terlihat dengan antusiasnya peserta saat sesi diskusi dan tanya jawab. Penyuluhan dekolonisasi bakteri resisten dengan mencuci tangan menurut WHO ini sangat dibutuhkan oleh masyarakat untuk melindungi mereka dari bakteri resisten yang bisa diperoleh dari mana saja. Hal ini sangat bermanfaat bagi mitra untuk mencegah penyebaran bakteri resisten di masyarakat.

\section{Saran}

Saran yang dapat direkomendasikan untuk pengabdian kepada masyarakat

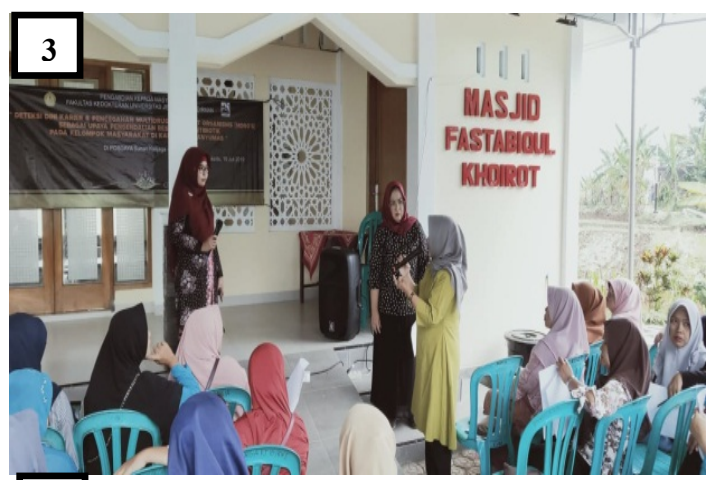

4

selanjutnya yaitu peserta dapat mempraktikan secara mandiri langkah-langkah mencuci tangan menurut WHO dalam aktivitas seharihari di rumah dan dapat mengedukasi anggota masyarakat lainnya di sekitar lingkungannya.

\section{DAFTAR PUSTAKA}

Anjarwati, D.U., Setyono, J., Rujito, L. 2011. Perawat kesehatan sebagai karier methicillin resistant Staphylococcus aureus (MRSA) di Rumah Sakit Pemerintah dan Rumah Sakit Swasta di Kabupaten Banyumas. Mandala of Health, 5(1).

Handayani, R.S., Siahaan, S., Herman, M.J. 2017. Antimicrobial Resistance and lts Control Policy Implementation in Hospital in Indonesia.Jurnal Penelitian dan Pengembangan Pelayanan Kesehatan, 1(2): 131-140.

Kurniawati, A.F.S., Satyabakti, P., Arbianti, M. 2015. Perbedaan risiko Multidrug Resistance Organism (MDRO's) menurut faktor risiko dan kepatuhan hand hygiene. Jurnal Berkala epidemiologi, 3(3): 277-289. 
Permenkes. 2015. Peraturan Menteri Kesehatan Republik Indonesia Nomor 8 Tahun 2015 Tentang Santosaningsih D., Zuhriyah L., Nurani M.P. 2011. Staphylococcus aureus pada Komunitas Lebih Resisten terhadap Ampisilin dibandingkan Isolat Rumah Sakit. Jurnal Kedokteran Brawijaya, 26(4): 204-07.

Ulla, I. M., Afifah and Anjarwati, D. U. 2018. Hubungan Riwayat Penggunaan Antibiotik Dengan Karier Eschericia coli Penghasil Extended Spectrum Beta Lactamase (ESBL) Pada Mahasiswa FK Unsoed Angkatan 2014. S1 Thesis. Universitas Jenderal Sudirman, Purwokerto.

WHO. 2009. Hand Hygiene, Why, How and When. www.who.int.

WHO. 2014. Antimicrobial Resistance Global Report on Surveilance www.who.int.
Program Pengendalian Resistensi Antimikroba Di Rumah Sakit. 